\title{
Dengue Fever and its Dermatological Changes
}

\author{
Mohan Kumar $\mathbf{R}^{\circledR 1}$, Muddu Surendra Nehru ${ }^{2}$ \\ ${ }^{1}$ Associate Professor, Department of General Medicine, Oxford Medical College, Bangalore, Karnataka, India, ${ }^{2}$ Associate Professor, Department of General Medicine, \\ Nimra Institute of Medical Sciences, Jupudi, Ibrahimpatnam, Krishna, Andhra Pradesh, India.
}

\section{Abstract}

Background: Around the world dengue incidence has dramatically grown with a large number of asymptomatic cases. Worldwide about 390 million dengue infections were occurring per year, among them 96 million people were developing clinical manifestations with varied severity. About 3.9 billion people residing in 128 countries, were at-risk of dengue virus infection. Dengue fever (DF) is one of the common causes of acute febrile illness. In half the patients with dengue fever skin involvement occurs. The aim of the study is to study the socio-demographic parameters, clinical features and laboratory parameters among the patients with and without skin rash in dengue infection. Also determine outcome among the patients with dengue fever and its association with skin rash. Subjects and Methods: A hospital-based, analytical prospective study was conducted in the Department of General Medicine, Sapthagiri Institute of Medical Sciences and Research Center, Bangalore. Patients older than 16 years of age with clinical features and laboratory reports suggestive of dengue infection were included. The study was conducted for a period of 12 months from 1st December 2014 to 30th November 2015. These patients were further divided based on the skin rash presence and absence. The data obtained was entered in Microsoft Excel and analyzed in SPSS version-22 trial. Analysis was done using unpaired students t-test, ANOVA. Results: In total 97 patients with dengue fever were enrolled into the study. About 14.4 p.c (14) patients were with skin rash. The patients with skin rash were found to have lower platelet levels during the disease course. Patients with skin rash had higher percentage of platelet transfusion which was statistically significant. Conclusion: A cutaneous involvement may facilitate clinical diagnosis but it may not be present among all the patients.

Keywords: Dengue Fever, Dengue Hemorrhagic Fever, Dermatological Rash

Corresponding Author: Muddu Surendra Nehru, Associate Professor, Department of General Medicine, Nimra Institute of Medical Sciences, Jupudi, Ibrahimpatnam, Krishna, Andhra Pradesh, India.

E-mail: surendra.muddu@gmail.com

Received: 26 January 2020

Revised: 22 February 2020

Accepted: 3 March 2020

Published: 18 May 2020

\section{Introduction}

Dengue a mosquito-borne, arboviral disease caused by a single-stranded positive-sense RNA virus belonging to Flaviviridae family with 4 distinct serotypes (DENV-1, DENV2, DENV-3 and DENV-4). ${ }^{[1,2]}$ It is transmitted by female Aedes mosquito mainly belonging to the species A.aegypti and A.albopictus. ${ }^{[3]}$ Infection with any one dengue serotype provides lifelong immunity to that serotype virus, but there is no cross-protective immunity to the other serotypes. ${ }^{[4]}$ Dengue virus infection among humans causes a spectrum of illnesses ranging from inapparent or mild febrile illness to dengue hemorrhagic fever (DHF) and dengue shock syndrome (DSS). ${ }^{[5]}$ Classic dengue fever characterized by sudden onset of fever (saddle-back), weakness, frontal headache, nausea and vomiting, anorexic, altered taste sensation, a mild sore throat, retroorbital pain, body aches, joint pains, bradycardia, petechiae, facial flushing and rash (scarlatiniform to maculopapular). ${ }^{[6,7]}$
WHO has simplified the differential diagnosis of DF and DHF/DSS based on the presence or absence of major organ involvement. ${ }^{[3,8]}$ Skin involvement occur commonly in DF. ${ }^{[9]}$ During recent years the incidence of dengue around the world has dramatically grown with a large number of asymptomatic cases so the

dengue cases which are actual present could not be reported and mostly misclassified. ${ }^{[1]}$ An estimate has indicated 390 million dengue infections per year of which 96 million were developing clinical manifestations with varied severity. ${ }^{[10]}$ Another study reported that about 3.9 billion people, in 128 countries, were at risk of infection with dengue viruses. ${ }^{[1]}$

\section{Aim \& Objectives}

- To study the demographic parameters among the dengue patients.

- To determine the clinical features and laboratory parameters among the dengue patients with and without skin 
rash.

- To determine outcome among the patients with dengue fever and its association with skin rash.

\section{Subjects and Methods}

A hospital-based, analytical prospective study was conducted in the Department of General Medicine, Sapthagiri Institute of Medical Sciences and Research Center, Bangalore. Patients older than 16 years of age with clinical features and laboratory reports suggestive of dengue infection were included. Patients with laboratory evidence of co-infection were excluded. The study was conducted for a period of 12 months from 1 st December 2014 to 30th November 2015. IEC approval and written consent were obtained in prior. The data obtained was entered in Microsoft Excel and analyzed in SPSS version22 trial. Analysis was done using unpaired students t-test, ANOVA. Based on the skin rash patients were divided into subjects with skin rash and without skin rash during their hospital visit. Patients with petechiae or skin lesions or both were identified to with skin rash. Other details regarding clinical features, laboratory investigations, organ involvement, treatment, and outcome were also recorded.

\section{Results}

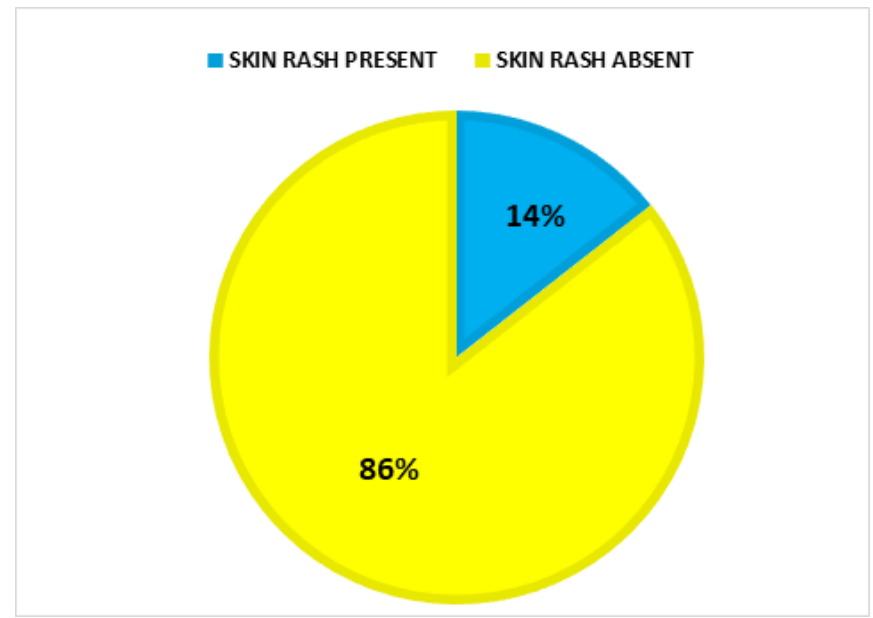

Figure 1: Distribution of Dengue Fever Patients Based on Skin Rash

About 97 patients with dengue fever were included in the present study. Patients with the presence of skin rash were $14(14.4 \%)$ and $83(85.6 \%)$ patients were without skin rash [Figure1]. Mean age among patients with skin rash was 29 years and 31 years among patients without skin rash (SN). In both the groups the mean duration of fever was 5-6 days. History of abdominal pain, gastrointestinal bleeding, hematuria, overt bleeding, epistaxis and gum bleeding were more among patients with skin rash when compared to patients without skin rash were statistically significant. Heart rate during admission, other variables (vital signs and hemogram) did not have a significant difference between the groups. Table 1 shows details of both the groups regarding socio-demographic parameters, clinical features and disease outcome. Patient with skin rash had lower levels of platelets. Alanine-amino transferase (ALT) or serum glutamic-pyruvic transaminase (SGPT) levels were abnormal in patients of both the groups. Heart rate and SGPT had shown a statistical significance. Platelet count during admission and lowest platelet during disease course were not significant. There was no difference in the sequential organ failure assessment score among both the groups. Table 2 shows various outcomes among both the groups, inpatient stay and platelet transfusion had a statistically significant association.

\section{Discussion}

In dengue fever, skin may be commonly involved which was found in about 50-82 p.c patients. ${ }^{[12]}$ Thomas EA et al, ${ }^{[13]}$ study reported skin involvement among more than 50 p.c of patients, in the present study skin involvement was seen among 14.4 p.c of the patients. In the similar study conducted by Huang et al, ${ }^{[9]}$ only a total of 45 patients included, patients without shin rash were older than that of present study, mean age of patients in both the groups were similar to that of present study. In the study conducted by Huang et al, ${ }^{[9]}$ patients without skin rash had thrombocytopenia and required more platelet transfusion, contrasting our findings of patients with skin rash who had lowest level of platelet and required more platelet transfusion. In the study conducted by Huang et al, ${ }^{[9]}$ only 5 (11 p.c) patients received platelet transfusion while in the present study 7 (7.2 p.c) patients had received platelet transfusion. Platelet transfusions across both the groups were statistically significant. Among the patients with skin rash platelet transfusion requirement, $\mathrm{O} 2$ requirement, non-invasive ventilation (NIV) requirement, inotropes requirement and dialysis requirement were of higher percentage but requirement of platelet transfusion had a statistically significant association with skin rash. Percentage of deaths was high among patients without skin rash was not statistically significant.

\section{Conclusion}

Dermatological involvement may facilitate clinical diagnosis of dengue but it may not be present among all the patients. 
Table 1: Socio-demographic parameters, laboratory findings, clinical features among dengue patients

\begin{tabular}{|c|c|c|}
\hline Variables & Dengue with skin rash $(n=14)$ & Dengue without skin rash $(n=83)$ \\
\hline Age $[$ Mean $\pm(S D)]$ & $29 \pm 10$ years & $31 \pm 13$ years \\
\hline Sex ratio (Male : Female) & $8: 6$ & $47: 36$ \\
\hline $\begin{array}{l}\text { Duration of fever in days [mean (min-- } \\
\max ) \text { ] }\end{array}$ & $5.5(3-11)$ & $5.8(1-20)$ \\
\hline Fever with chills & $10(71.4 \%)$ & $61(73.4 \%)$ \\
\hline Myalgia & $13(92.8 \%)$ & $71(85.5 \%)$ \\
\hline Arthralgia & $3(21.4 \%)$ & $9(10.4 \%)$ \\
\hline Headache & $10(71.4 \%)$ & $52(62.6 \%)$ \\
\hline Vomiting & $7(50 \%)$ & $37(44.5 \%)$ \\
\hline Abdominal pain & $4(28.5 \%)$ & $16(19.2 \%)$ \\
\hline Loose stool & $3(21.4 \%)$ & $6(7.2 \%)$ \\
\hline Dyspnoea & $1(7.1 \%)$ & $6(7.2 \%)$ \\
\hline Cough & $3(21.4 \%)$ & $11(13.2 \%)$ \\
\hline Low sensorium & $1(7.1 \%)$ & $3(3.6 \%)$ \\
\hline Overt bleeding & $4(28.5 \%)$ & $18(21.6 \%)$ \\
\hline Gastrointestinal bleeding & $3(21.4 \%)$ & $5(6.02 \%)$ \\
\hline Epistaxis & $2(14.2 \%)$ & $3(3.61 \%)$ \\
\hline Haematuria & $2(14.2 \%)$ & $2(2.4 \%)$ \\
\hline Gum bleeding & $1(7.1 \%)$ & $4(4.8 \%)$ \\
\hline Heart Rate (MEAN + SD) & $101+16$ & $96+14$ \\
\hline Mean systolic BP, mmHg (SD) & $104+13$ & $106+14$ \\
\hline Mean diastolic BP, mmHg (SD) & $69+11$ & $69+12$ \\
\hline Mean RR, per minute (SD) & $22+4$ & $20+4$ \\
\hline Mean $\mathrm{SpO} 2, \%(\mathrm{SD})$ & $96.6+2.31$ & $96.4+4.8$ \\
\hline Mean $\mathrm{Hb}, \mathrm{g} \%$ (SD) & $14.5+2.3$ & $14.5+2.1$ \\
\hline Mean WBC/mm3 & 5489 & 5338 \\
\hline Day 1 Mean Platelet/mm3 & 65,364 & 78,445 \\
\hline Mean Creatinine, mg\% & $1.18+0.5$ & $1.17+0.4$ \\
\hline Mean Urea, mg\% & $24+14$ & $26+15$ \\
\hline Mean Protein, g/dl & $6.91+0.9$ & $6.92+0.8$ \\
\hline Mean Albumin, g/dl & $3.8+0.6$ & $3.9+1.8$ \\
\hline Mean SGOT, U/L & 240 & 238 \\
\hline Mean SGPT, U/L & 190 & 101 \\
\hline Mean Alkaline phosphate, U/L & 108 & 93 \\
\hline
\end{tabular}




\begin{tabular}{|c|c|c|c|c|}
\hline Variables & & Skin rash present & Skin rash absent & p-value \\
\hline \multirow[t]{2}{*}{ Inpatient stay } & Yes & $2(14.2 \%)$ & $33(39.7 \%)$ & 0.002 \\
\hline & No & $12(85.8 \%)$ & $50(60.3 \%)$ & \\
\hline \multirow[t]{2}{*}{ Platelet transfusion } & Yes & $2(14.2 \%)$ & $5(6.2 \%)$ & 0.024 \\
\hline & No & $12(85.8 \%)$ & $78(93.8 \%)$ & \\
\hline \multirow[t]{2}{*}{ Oxygen (O2) } & Yes & $1(7.1 \%)$ & $2(2.4 \%)$ & 0.356 \\
\hline & No & $13(92.9 \%)$ & $81(97.6 \%)$ & \\
\hline \multirow[t]{2}{*}{ Requirement of NIV } & Yes & $1(7.1 \%)$ & $3(3.6 \%)$ & 0.098 \\
\hline & No & $13(92.9 \%)$ & $80(96.4 \%)$ & \\
\hline \multirow[t]{2}{*}{ Requirement of } & Yes & $1(7.1 \%)$ & $3(3.6 \%)$ & 0.098 \\
\hline & No & $13(92.9 \%)$ & $80(96.4 \%)$ & \\
\hline \multirow[t]{2}{*}{ Requirement of } & Yes & $1(7.1 \%)$ & 0 & - \\
\hline & No & $13(92.9 \%)$ & $83(100 \%)$ & \\
\hline \multirow[t]{2}{*}{ Death } & Yes & 0 & $3(3.6 \%)$ & - \\
\hline & No & $14(100 \%)$ & $80(96.4 \%)$ & \\
\hline
\end{tabular}

\section{References}

1. Back AT, Lundkvist A. Dengue viruses - an overview. Infect Ecol Epidemiol. 2013;3:1-21. Available from: https://dx.doi. org/10.3402/iee.v3i0.19839.

2. Abhilash KPP, Mitra S, Gautam I, Jambugulam M, Jayaseeelan V. Clinical score to differentiate scrub typhus and dengue: A tool to differentiate scrub typhus and dengue. J Global Inf Dis. 2017;9:12-17. Available from: https://dx.doi.org/10.4103/ 0974-777x.199996.

3. Koshy M, Mishra AK, Agrawal B, Kurup AR, Hansdak SG. Dengue fever complicated by hemophagocytosis. Oxford Medical Case Reports. 2016;2016:121-124. Available from: https://dx.doi.org/10.1093/omcr/omw043.

4. Gubler DJ. Epidemiology of arthropod-borne viral diseases. Monath TP, editor. Boca Raton, Fla: CRC Press, Inc; 1988.

5. Gubler DJ. Dengue and Dengue Hemorrhagic Fever. Clin Microbiol Rev. 1998;11(3):480-496.

6. Hayes EB, Gubler DJ. Dengue and dengue hemorrhagic fever. Pediatric Inf Dis J. 1992;11(4):311-317. Available from: https: //dx.doi.org/10.1097/00006454-199204000-00010.

7. Cassetti MC, Thomas SJ. Dengue Human Infection Model: Introduction. J Infect Dis. 2014;209(Suppl 2):S37-S39. Available from: https://dx.doi.org/10.1093/infdis/jiu061.

8. Simmons CP, Farrar JJ, V NV, Wills B, Dengue. N Engl J Med. 2012;12(15):1423-1455.

9. Thomas EA, John M, Kanish B. Mucocutaneous manifestations of Dengue fever. Indian J Dermatol. 2010;55(1):79-85. Available from: https://dx.doi.org/10.4103/0019-5154.60359.
10. Bhatt S, Gething PW, Brady OJ, Messina JP, Farlow AW, Moyes CL. The global distribution and burden of dengue. Nature. 2013;496(7446):504-507. Available from: https://dx. doi.org/10.1038/nature12060.

11. Brady OJ, Gething PW, Bhatt S, Messina JP, Brownstein JS, Hoen AG, et al. Refining the Global Spatial Limits of Dengue Virus Transmission by Evidence-Based Consensus. PLoS Neglected Trop Dis. 2012;6:e1760-e1760. Available from: https://dx.doi.org/10.1371/journal.pntd.0001760.

12. Waterman SH, Gubler DJ. Dengue fever. Clin Dermatol. 1989;7(1):117-122. Available from: https://dx.doi.org/10. 1016/0738-081x(89)90034-5.

13. Thomas E, John M, Kanish B. Mucocutaneous manifestations of dengue fever. Indian J Dermatol. 2010;55:79-85. Available from: https://dx.doi.org/10.4103/0019-5154.60359.

Copyright: (C) the author(s), 2020. It is an open-access article distributed under the terms of the Creative Commons Attribution License (CC BY 4.0), which permits authors to retain ownership of the copyright for their content, and allow anyone to download, reuse, reprint, modify, distribute and/or copy the content as long as the original authors and source are cited.

How to cite this article: Kumar R M, Nehru MS. Dengue Fever and its Dermatological Changes. Acad. J Med. 2020;3(1):11-14.

DOI: dx.doi.org/10.47008/ajm.2020.3.1.3

Source of Support: Nil, Conflict of Interest: None declared. 